\title{
Perception of Safety, Importance, and Effectiveness of Vaccinations Among Urban School Employees in Utah
}

\author{
Karlen E. Luthy \\ Brigham Young University - Provo, beth-luthy@byu.edu \\ Kim E. Thompson \\ Renea L. Beckstrand \\ Brigham Young University - Provo \\ Janelle L B Macintosh \\ BYU \\ Lacey M. Eden \\ BqHlow this and additional works at: https://scholarsarchive.byu.edu/facpub \\ Part of the Nursing Commons
}

\section{Original Publication Citation}

Luthy, K. E., Thompson, K. E., Beckstrand, R. L., Macintosh, J. L., \& Eden, L. M. (2015). Perception of safety, importance, and effectiveness of vaccinations among urban school employees in Utah. Journal of the American Association of Nurse Practitioners, 27(6), 313-320. doi:10.1002/ 2327-6924.12233

\section{BYU ScholarsArchive Citation}

Luthy, Karlen E.; Thompson, Kim E.; Beckstrand, Renea L.; Macintosh, Janelle L B; and Eden, Lacey M., "Perception of Safety, Importance, and Effectiveness of Vaccinations Among Urban School Employees in Utah" (2015). Faculty Publications. 1774.

https://scholarsarchive.byu.edu/facpub/1774

This Peer-Reviewed Article is brought to you for free and open access by BYU ScholarsArchive. It has been accepted for inclusion in Faculty Publications by an authorized administrator of BYU ScholarsArchive. For more information, please contact ellen_amatangelo@byu.edu. 
Perception of Safety, Importance, and Effectiveness of Vaccinations

Among Urban School Employees in Utah

Karlen E. Luthy, DNP, FNP Associate Professor College of Nursing, Brigham Young University

Beth_Luthy@byu.edu

Kim E. Thompson, MS, FNP-S

College of Nursing, Brigham Young University

Dkthompson7@msn.com

Renea L. Beckstrand, PhD, RN, CCRN, CNE Professor

College of Nursing, Brigham Young University

Renea_beckstrand@byu.edu

Janelle L. B. Macintosh, PhD, RN Assistant Professor

College of Nursing, Brigham Young University

Janelle_Macintosh@byu.edu

Lacey M. Eden, MS, NP-C Assistant Teaching Professor

(Contact Author)

College of Nursing, Brigham Young University

535 SWKT Provo, UT 84602

(801) 422-6891 Office

(801) 422-0536 Fax

Lacey_eden@byu.edu 


\begin{abstract}
Purpose: School employees are in direct contact with children in confined areas, a setting in which communicable infection can quickly spread. Therefore, it is important for school employees to be fully vaccinated. The purpose of this study is to ascertain the current vaccination status and perceptions of school employees in an urban school district.

Data Sources: The study employed a nonexperimental mixed-method design. School employee participants $(\mathrm{N}=1,400)$ completed a questionnaire to evaluate vaccination status, availability of vaccination records, and vaccination awareness. Participants were randomly selected from 85 schools within one urban school district.

Conclusions: Two common perceptions about vaccines emerged from the questionnaire: 1) vaccines are only for children and 2) vaccinations received during childhood are still effective. School employees are unaware of their own vaccination status and the recommended vaccination schedule for adults. Additionally, accessibility to immunization records for adults are frequently inadequate.

Implications for Practice: Healthcare providers (HCP), including nurse practitioners, are the first line of defense to ensure adults are adequately vaccinated. When vaccinations are tracked and recommended by HCPs vaccination uptake is improved. Nurse practitioners who discuss recommended vaccinations with adult patients are instrumental in improving vaccination rates among school employees.
\end{abstract}




\section{Introduction}

During the $20^{\text {th }}$ century, deaths from infectious diseases have drastically declined due to the advent of vaccines (Centers for Disease Control and Prevention [CDC], 1999; Choi \& Manning, 2010). In 1974, the World Health Organization established the Expanded Programme on Immunization to ensure children had universal access to routinely recommended childhood vaccines (World Health Organization [WHO], 2011). Six vaccine-preventable diseases were initially targeted: tuberculosis, poliomyelitis, diphtheria, tetanus, pertussis, and measles. At that time less than 5\% of the world's infants were fully vaccinated (WHO, 2011). However, by 2012 global coverage of vaccines had significantly improved. Worldwide, the vaccination rate for hepatitis B is now 79\%. Vaccination rates for haemophilus influenza type B and diphtheriatetanus-pertussis have also improved to $45 \%$ and $83 \%$, respectively (WHO, 2014).

Over the last four decades in the United States (US) several vaccine-preventable diseases have been eradicated or controlled due to routine childhood vaccinations (Glanz et al., 2009). For example, after widespread vaccination with smallpox vaccine, smallpox cases were non-existent by 1979 (Glanz et al., 2009). In addition to smallpox, poliomyelitis has been eliminated in the US, measles has also achieved elimination status (with only imported cases since 2000), and Haemophilus influenza cases have decreased to 1.6 in 100,000 people (CDC, 2012a). However, in order to maintain the low incidence of vaccine-preventable diseases in the US, vaccination compliance must be maintained otherwise there will be a resurgence of these diseases (CDC, 2012b).

While the reduction of these childhood illnesses has benefitted society, one unintended consequence is that public concern has now shifted from preventing disease with vaccinations to questioning vaccine safety (Choi \& Manning, 2010; Glanz et al., 2009). Although vaccination 
rates remain high nationally for many vaccines, clusters of unvaccinated people in some communities have left many people vulnerable to outbreaks of disease (CDC, 2012b; Omer et al., 2008). For example, since 2011 a 1,300\% increase in pertussis infections have been reported in the state of Washington, the highest number of pertussis cases in any year since 1942 (CDC, 2012c). Similarly, in April 2011 there was an outbreak of measles in Utah after a family with unvaccinated children returned from international travel to Poland. The Utah measles outbreak affected one school district that prompted the quarantine of many teachers and students because they were either inadequately immunized against the measles or unsure of their vaccination status (Stewart, 2011).

Individuals who work with children are at risk for exposure to vaccine-preventable diseases (Luthy, Thornton, Beckstrand, Macintosh, \& Lakin, 2013b). Because school employees are in direct contact with children in confined areas for many hours each day, school settings can quickly become outbreak centers for communicable infection. Thus, it is important for school employees to be fully vaccinated (CDC, 2012d; Gargano et al., 2011). The Utah Department of Health (2012) currently recommends adult vaccinations specifically for employees of schools and childcare facilities to prevent the spread of vaccine-preventable diseases. However, not all Utah school districts may be aware of these recommendations. While rural school employee vaccination status and perceptions have been studied in Utah, the vaccination status and perceptions of Utah's urban school employees remains unknown. The purpose of this study, therefore, is to ascertain the perception of safety, importance, and effectiveness of school employee vaccinations in an urban Utah school district, as well as to assess their action plan in the event of a measles outbreak. 


\section{Research Inquiries}

1. Examine urban Utah school district employees description of their personal vaccination status.

2. Assess the perceptions of urban Utah school district employees regarding needed adult vaccinations.

3. Explore discussions between urban Utah school district employees and their healthcare provider $(\mathrm{HCP})$.

4. Discover urban Utah school district employee's work-related action plan in the event of a measles outbreak at their school.

\section{Methodology}

The researchers received approval from the Institutional Review Board prior to collecting data. The urban Utah study, a nonexperimental mixed-method design, replicated a previous study conducted in rural Utah.

Setting. The urban school district was located in the greater Salt Lake City area, in the third most populous county in the State of Utah. Within the school district, special education, language emersion, and multiple Title I programs were offered. In addition, the district offered migrant education, Indian education, and homeless population education services.

Participant. Within one urban Utah school district, 1,400 participants were randomly selected by computer from 85 sites according to place of employment, such as the type of school or district office. Randomly selected sites included: 20 elementary, four junior high, two senior high, and seven district offices, which provided a matched sample to a study conducted the previous year in a rural Utah school district. Principals from two of the 20 elementary schools denied having questionnaires delivered to their respective school locations because they were 
concerned it would be a burden to the school employees. Of the seven district offices randomly selected for participation, one refused to participate because they were in the process of relocating their office. Questionnaires were delivered to the remaining 18 elementary schools, six district offices, four junior high schools, and two senior high schools for a total of 1259 questionnaires distributed. To be eligible for participation, participants needed to be employed in any capacity, either full-time or part-time, by the school district. Excluded from participation were school volunteers and teacher aides because this population tends to be transient by nature and, as a result, may not accurately represent the views of permanent employees.

Instrument. The instrument was adapted from a questionnaire created for use in a Utah pilot study (Luthy, Houle, Beckstrand, Macintosh, \& Lakin, 2013a), and then utilized again with a larger sample to measure vaccination perceptions among rural Utah school employees (Luthy et al., 2013b). The instrument was originally created by a team of Utah public health experts who pre-tested the questionnaire prior to its first use in the pilot study. Because the instrument was designed by public health experts and pre-tested, its face validity was not reevaluated prior to use in this study. The two page adapted questionnaire included $10 \mathrm{yes} /$ no, seven multiple choice, two open-ended, and seven demographic questions.

The 10 yes/no items were designed to evaluate the school employees' vaccination status, availability of vaccination records, and vaccination awareness. Specifically, participants were asked if they were fully vaccinated, could find their vaccination record, were aware of any vaccination requirements for school employees, and were up-to-date on four particular vaccinations: 1) influenza (flu), 2) MMR as a child and as an adult, 3) tetanus-diphtheria (Td), and 4) tetanus with pertussis (Tdap). If participants were unsure of any of their answers to these questions, they had the option of selecting "I don't know" as a response. Participants were also 
questioned about whether or not their HCP had discussed vaccinations with them. In lieu of a yes/no response, participants could also choose to report the absence of a HCP. Finally, participants were asked about their beliefs regarding the need for a mandatory vaccination requirement for school employees. Instead of selecting the yes/no choices participants could choose the response "undecided." Some of the yes/no items also included space where the participants could share comments regarding their response.

The multiple choice items included perception-related questions on vaccination safety and importance, space for an explanation as to why the subject's flu and MMR vaccines were out-ofdate, and action plan in the event of a measles outbreak at their school. Likert-style questions related to vaccination safety and importance included six choices: strongly agree, agree, no opinion, disagree, strongly disagree, and "other." When asked to report on the participants' planned action in the event of a measles outbreak at their school, choices for responses included: 1) I have had an MMR booster so I'd stay at work, 2) I'm unsure of my MMR status but I'd stay at work, 3) I've already had the measles so I'd stay at work, 4) I have not had an MMR booster but I'd stay at work, 5) I have had an MMR booster but would stay at home, 6) I have not had an MMR booster so I'd stay at home, and 8) Other. The "other" choice included space where the subject could clarify their response.

Seven demographic questions were included in the questionnaire, asking individuals to report their gender, age, and employment status (either full-time or part-time). Individual respondents were also asked to report how many years they had worked as an employee in that school district and in what capacity they were employed (such as teacher, support staff, or administrator). Lastly, individuals were asked to disclose their ethnicity and where they were employed (such as elementary, junior high, high school, or district office). 
Design. The study was approved by the school district's director of assessment, research, $\&$ evaluation. A few weeks prior to the distribution of the questionnaires each of the district directors, school principals, and secretaries were contacted by email concerning the study.

Upon delivery of the questionnaires at each participating site, secretaries received directions on how to distribute the study to employees. Secretaries were asked to e-mail each fulltime and part-time employee at their school to announce the study and the presence of a questionnaire in each individual's school mailbox. The informed consent document and return address envelope, with pre-paid postage, was stapled to each questionnaire. In addition, a \$1.00 bill was attached to each questionnaire as an incentive for participation. Regardless of their participation in the study, the employee could keep the $\$ 1.00$ incentive. Return of the questionnaire provided implied consent.

Data Analysis. Data were entered into SPSS 19 (SPSS Inc., Chicago, IL, 2012). Frequencies, measures of central tendency and dispersion, and reliability statistics were calculated for all quantitative items. Qualitative data from the "comment" and "other" responses on the questionnaire were independently reviewed by two researchers and analyzed to identify common themes.

\section{Results}

A total of 1,259 questionnaires were delivered to full-time and part-time employees of the selected urban Utah school district to measure their perceptions of safety, importance, and effectiveness of vaccinations; 852 questionnaires were returned for a response rate of $67 \%$. Of those who responded, $695(84.5 \%)$ were female and $127(15.5 \%)$ were male. With regard to employment status, 710 (85.7\%) worked full-time, while 114 (13.8\%) worked part-time in the school district. The age range of respondents was 22 years to 78 years with a mean age of 46 (SD 
11.324) years. The amount of time spent working in the school district ranged from 1 year to 55 years, with a mean of $12.9(\mathrm{SD} 8.962)$ years (see Table 1).

Current Vaccination Status. Several items on the questionnaire were meant to ascertain the current vaccination status of urban Utah school district employees. Of the 852 participants, 625 (74.7\%) considered themselves to be fully vaccinated, 112 (13.4\%) reported they were not fully vaccinated, and $100(11.9 \%)$ were unsure if they were fully vaccinated. However, when questioned about specific vaccinations, only $317(37.8 \%)$ of the participants reported having received the flu vaccine for the current season, although another $522(62.2 \%)$ reported being unvaccinated against flu. In comparison, 519 (61.9\%) reported their Td booster was updated in the last 10 years. When questioned about whether their last $\mathrm{Td}$ booster included protection against pertussis, only 227 (42.1\%) of participants confirmed they had received a Tdap. Regarding the MMR vaccination, 616 (77.6\%) of participants reported having received the MMR vaccine as a child, while 290 (34.0\%) reported having received the MMR vaccine as an adult (See Table 2).

In addition to answering specific questions about their current vaccination status, participants also had the option to provide additional comments. There were two major themes that emerged from additional comments: 1) a need for guidance on boosters $(\mathrm{n}=16)$, and 2$)$ specific refusal of the flu vaccine $(n=12)$. Some employees wanted information about which of their childhood vaccinations needed a booster while other employees were curious if they needed any of the newer vaccines on the market. Such thoughts were evidenced by comments including, "I [may be] due for some boosters," "I have heard recently that boosters are now needed for diseases we thought were life-time immunizations, but don't know which ones," and "I know that there are new immunizations that are suggested but I don't know if I need them." The second theme - specific refusal of the flu vaccine - included comments by some school employees who 
consistently refused the flu vaccine, but also by others who inconsistently updated their flu vaccine. The theme was captured in comments such as, "I [do not] get flu shots," and "[All] except [the] flu shot."

Vaccination records. Participants were also asked if they would be able to locate their personal vaccination records, if needed. Of those who responded, 344 (41.3\%) stated they would be able to locate their vaccination records, although 485 (58.3\%) of participants were either unsure or confirmed they would be unable to locate their vaccination records. The participants who wrote in additional comments about locating their vaccination records $(n=87)$ believed they could, in fact, produce a copy of the record if given enough time. This theme emerged from comments such as, "I would [have to] ask my doctor to print them" and "I know the health department has them." Additionally participants reported that while they might be able to locate their records, these records would likely be incomplete. Such thoughts were captured in comments such as, "Partly I have my childhood records, but I don't keep track of my adult immunizations" and "Not sure how accurate they are; they don't go back very far."

Vaccination Perceptions. Several items in the questionnaire were meant to assess school employees' perceptions of the safety, importance, and effectiveness of vaccinations. Of the 852 participants, $780(92.9 \%)$ either agreed or strongly agreed vaccinations were safe, 794 (94.5\%) agreed or strongly agreed vaccinations prevented disease, 670 (79.8\%) agreed or strongly agreed adults should receive vaccinations, and 790 (94.1\%) agreed or strongly agreed school-aged children should receive vaccinations. When questioned about adult vaccination mandates, 389 $(46.3 \%)$ believed there should be mandatory vaccination requirements for school district employees, $224(26.7 \%)$ were undecided about mandatory vaccination requirements, and 227 $(27.0 \%)$ were opposed to mandatory vaccination requirements. Only $46(5.5 \%)$ participants 
mistakenly believed there were already mandatory vaccination requirements in place for school district employees. The remaining vaccination perception data are reported in Table 3.

HCP information. Participants were also asked whether or not their HCP had informed them about adult vaccinations. Of those responding, 352 (42\%) reported having a conversation with their HCP regarding adult vaccinations although 465 (55.5\%) reported their HCP had not discussed adult vaccinations with them. Only 21 (2.5\%) said they had no HCP with whom they could discuss adult vaccinations (See Table 4).

In addition, participants could include comments regarding adult vaccination information received from their HCPs. Of the 38 comments, two main themes became apparent: 1) the HCP often only recommended the flu vaccine $(\mathrm{n}=10)$, and 2) participants felt their HCP did not offer much information on vaccinations $(n=7)$. The first theme, that HCP often only recommended the flu vaccine, was captured in comments such as "They asked me if I wanted a flu shot." The second theme, that participants felt their provider did not offer much information on vaccinations, was expressed in comments such as "I wish they would [offer information on vaccines]," "Not very extensively," or "I brought it up though, he did not."

Action Plan in the Event of a Measles Outbreak. Participants were asked about their workrelated action plan if there was a measles outbreak in their school. Of those responding, 611 (74\%) reported they would stay at work during a measles outbreak, $160(19.3 \%)$ reported they would stay home during a school-based measles outbreak, and $55(6.7 \%)$ were unsure of their action in the event of a measles outbreak. Of the 611 participants planning to stay at work during a measles outbreak, only 246 (29.8\%) had received an MMR booster, 161 (19.5\%) were unsure of their MMR status, $131(15.9 \%)$ had the measles disease during their lifetime, and $73(8.8 \%)$ were sure they had not received an MMR booster. Of those 160 participants who reported that they would stay 
home during a measles outbreak, 33 (4.0\%) had received an MMR booster, $45(5.4 \%)$ had not received an MMR booster, and $82(9.9 \%)$ were unsure of their MMR status. The remaining data concerning the participants' planned action in the event of a measles outbreak is reported on Table

5.

\section{Discussion}

In September 2013, the National Vaccine Advisory Committee (NVAC) updated the standards for immunization of adults, although they also acknowledged low vaccination uptake among adults. Williams et al. (2014) reported a mere $12.2 \%$ of American adults are up-to-date on the hepatitis A vaccine, only $14.2 \%$ are current on Tdap vaccine, and $20.1 \%$ are adequately vaccinated against shingles. The belief that vaccines are only for children is a common reason for poor vaccine compliance among adults (CDC, 2014a; Immunization Action Coalition, 2012). Our research also supports these findings since the school employees perceived vaccinations as important for school-aged children more frequently than for adults.

Because schools can serve as outbreak centers for communicable disease, all 50 states require childhood vaccines prior to school entry. Since school employees work in an environment which promotes the rapid spread of communicable and vaccine-preventable diseases, it was surprising that the vaccination rates of the Utah school employees and the average American adult were similar in spite of Utah Department of Health recommendations for adults working in school settings. For example, in this study the participants who had received a $\mathrm{Td}$ booster in the last 10 years differed by only a few points from the national vaccination rate of Td (CDC, 2014b). Additionally, flu vaccine uptake is continually reported as suboptimal in all adults, with similar vaccination rates between the Utah school employees and adults nationwide (CDC, 2013). 
According to national guidelines, an individual exposed to the measles virus during an outbreak must provide evidence of immunity through 1) documentation of vaccination, 2) laboratory titers, 3) birth before 1957, or 4) laboratory confirmation of the disease. If none of these criteria are satisfied, the susceptible contact is subsequently quarantined (Kutty et al., 2014). The school employees in this study, however, were unfamiliar with these guidelines since some of the employees reported that they planned to continue working even though they were either unsure of their MMR status or confirmed they had never received an MMR booster. As a result of study findings, it is advisable for school districts to include measles outbreak planning as part of their disaster preparedness training. Additionally, having a record of MMR status on each school employee prior to a measles outbreak would save significant time and money in the event of a measles outbreak.

Implications for Practice. HCPs are in a prime position to assess an adult's vaccination status at each clinic visit and then promote vaccinations among adult patients (Bridges, CoyneBeasley, Advisory Committee on Immunization Practices (ACIP), \& ACIP Adult Immunization Work Group, 2014). In this study, however, over half the participants reported never discussing adult vaccinations with their HCP and, even when vaccinations were discussed, the HCP usually only discussed the flu vaccine. NPs, similar to all HCPs, are encouraged to "take steps to help ensure that their adult patients are fully immunized" (CDC, 2014c, para. 1). While pharmacies and other retail businesses may offer adult vaccinations outside the traditional clinic environment, the majority of adults still receive their vaccinations at the $\mathrm{HCP}$ office where they can discuss the benefits and risks of vaccination with a provider who is already familiar with their health history and who can assist in keeping vaccination records (Voelker, 2012). 
Unfortunately, many HCPs miss opportunities to vaccinate their adult patients (Hurley et al., 2014), even though the majority of patients will, in fact, receive vaccinations if recommended by the HCP (Johnson, Nichol, \& Lipczynski, 2008). To overcome missed opportunities, the NP should review the vaccination status of all patients during every clinic visit. To assist the NP in this process, medical assistants can be trained to provide an initial review of the patient's health record for missing immunizations. Multiple vaccination training resources are available free of charge at http://www.cdc.gov/vaccines/ed/courses.htm. Additionally, the medical assistant can provide vaccination handouts to adult patients immediately following vital sign assessment, thus allowing the patient a few minutes to review adult vaccination information while waiting for the HCP to enter the clinic room. Various vaccination handouts are available and free to download from the Immunization Action Coalition at http://www.immunize.org/handouts/top-picks.asp. Furthermore, many electronic health record (EHR) systems have a feature that will alert the HCP if a patient is overdue for a vaccination which, in turn, positively influences vaccination rates among patients ( $\mathrm{Au}$, Oster, Yeh, Magno, \& Paek, 2010). If this feature of the EHR is not yet fully utilized, the NP may want to facilitate its use in his or her clinic.

Limitations. Participants were selected from paid employees of one urban Utah school district. As a result, this sample may not accurately represent the views of the volunteers in the school urban Utah school district, volunteers of other school districts, or employees of private or charter schools. Because this study was conducted in urban Utah, the findings may not be generalizable to other school districts in the state of Utah or in the US. Furthermore, including responses from school employees who refused to participate could have altered the results. 
Recommendations for Further Research. Replicating the same study among school employees in private or charter schools may reveal similarities or differences between the urban school employees and school employees of other school districts. It may be of benefit to pilot an adult vaccination education program and evaluate whether such a program truly impacts the opinion of school employees who are undecided regarding vaccination mandates in their school districts.

\section{Conclusion}

School employees are at risk for contracting and spreading vaccine-preventable diseases when inadequately vaccinated. Thus, the vaccination status of adults, especially those working in the school setting, should be regularly assessed. Most adults, however, are unaware of the vaccines recommended for individuals over 18 years of age and are dependent on HCPs, such as NPs, to provide this important information. HCPs constitute the first line of defense to ensure adults are adequately vaccinated and, when vaccinations are tracked and recommended by HCPs, vaccination uptake is improved among patients. NPs can be instrumental in facilitating clinic policy changes which, in turn, improve vaccination rates among adults. 


\section{References}

Au, L, Oster, A., Yeh, G. H., Magno, J., \& Paek, H. M. (2010). Utilizing an electronic health record system to improve vaccination coverage in children. Applied Clinical Informatics, 14(3), 221-231. doi: 10.4338/ACI-2009-12-CR-0028

Bridges, C. B., Coyne-Beasley, T., Advisory Committee on Immunization Practices (ACIP), \& ACIP Adult Immunization Work Group. (2014). Advisory committee on immunization practices recommended immunization schedule for adults ages 19 years or older - United States, 2014. Morbidity and Mortality Weekly Report, 63(5), 110-112.

Centers for Disease Control and Prevention. (1999). Achievements in public health, 1900-1999: Impact of vaccines universally recommended for children - United States, 1990-1998. Morbidity and Mortality Weekly Report, 48(12), 243-248.

Centers for Disease Control and Prevention. (2012a). Measles - United States, 2011. Morbidity and Mortality Weekly Report, 61(15), 253-254.

Centers for Disease Control and Prevention. (2012b). National, state, and local area vaccination coverage among children aged 19-35 months — United States. Morbidity and Mortality Weekly Report, 61(35), 689-696.

Centers for Disease Control and Prevention. (2012c). Pertussis epidemic - Washington, 2012. Morbidity and Mortality Weekly Report, 61(28), 517-522.

Centers for Disease Control and Prevention. (2012d). School starts soon - Is your child fully vaccinated? Retrieved from http://www.cdc.gov/features/catchupimmunizations/ Centers for Disease Control and Prevention. (2013). Flu vaccination coverage, United States, 2012-13 influenza season. Retrieved from http://www.cdc.gov/flu/fluvaxview/coverage1213estimates.htm 
Centers for Disease Control and Prevention. (2014a). Advisory committee on immunization practices recommended immunization schedule for adults aged 19 years or older United States, 2014. Morbidity and Mortality Weekly Report, 63(5), 110-112. Retrieved from http://www.cdc.gov/mmwr/preview/mmwrhtml/mm6305a7.htm

Centers for Disease Control and Prevention. (2014b). Noninfluenza vaccination coverage among adults - United States, 2012. Morbidity and Mortality Weekly Report, 63(5), 95-102.

Centers for Disease Control and Prevention. (2014c). Overview: A series on standards for adult immunization practice. Retrieved from http://www.cdc.gov/vaccines/hcp/patiented/adults/downloads/standards-immz-practice.pdf

Choi, B. K., \& Manning, M. L. (2010). The immunization status of home-schooled children in America. Journal of Pediatric Health Care, 24(1), 42-47. doi:10.1016/jpedhc.2009.02.002

Gargano, L. M., Painter, J. E., Sales, J. M., Morfaw, C., Jones, L. M., Murray, D., . . Hughes, J. M. (2011). Seasonal and 2009 H1N1 influenza vaccine uptake, predictors of vaccination, and self-reported barriers to vaccination among secondary school teachers and staff. Human Vaccines, 7(1), 89-95.

Glanz, J. M., McClure, D. L., Magid, D. J., Daley, M. F., France, E. K., Salmon, D. A., \& Hambidge, S. J. (2009). Parental refusal of vaccination is associated with an increased risk of pertussis infection in children. Pediatrics, 123(6), 1446-1451. doi:10.1542/peds.2008-2150

Hurley, L. P., Bridges, C. B., Harpaz, R., Allison, M. A., O’Leary, S. T., Crane, L. A., ...Kempe, A. (2014). U. S. physicians' perspective of adult vaccine delivery. Annals of Internal Medicine, 160(3), 161-170. doi:10.7326/M13-2332 
Immunization Action Coalition. (2012). Adults only vaccination: A step-by-step guide. St. Paul, MN: Immunization Action Coalition.

Johnson, D. R., Nichol, K. L., \& Lipczynski, K. (2008). Barriers to adult immunization. The American Journal of Medicine, 121(7 Suppl 2), S28-S35.

Kutty, P., Rota, J., Bellini, W., Redd, S. B., Barskey, A., \& Wallace, G. (2014). Retrieved from http://www.cdc.gov/vaccines/pubs/surv-manual/chpt07-measles.html

Luthy, K. E., Houle, K., Beckstrand, R. L., Macintosh, J., \& Lakin, R. G. (2013a). Vaccination perceptions and barriers of school employees: A pilot study. Journal of School Nursing, 29(4), 284-293. doi:10.1177/1059840513490029

Luthy, K. E., Thornton, E., Beckstrand, R. L., Macintosh, J., \& Lakin, R. G. (2013b). Rural school employees' status, awareness and perceptions of adult vaccinations. Journal of School Nursing, 29(4), 294-302. doi: 10.1177/1059840513491118

National Vaccine Advisory Committee. (2013). Update on the National Vaccine Advisory Committee standards for adult immunization practice. Retrieved from http://www.hhs.gov/nvpo/nvac/reports/nvacstandards.pdf

Omer, S. B., Enger, K. S., Moulton, L. H., Halsey, N. A., Stokley, S. S., \& Salmon, D. A. (2008). Geographic clustering of nonmedical exemptions to school immunization requirements and associations with geographic clustering of pertussis. American Journal of Epidemiology, 168(12), 1389-1396. doi:10.1093/aje/kwn263

Stewart, K. (2011, April). Measles outbreak linked to returned missionary’s family. Salt Lake Tribune. Retrieved from http://www.sltrib.com/sltrib/news/51614160-78/measles-healthvirus-parents.html.csp 
Utah Department of Health. (2012). Utah school and childcare employee immunization recommendations. Retrieved from http://health.utah.gov/immu/pdf/Utah\%20School \%20and\%20Childcare\%20Employee\%20Immunization\%20Recommendations.pdf

Voelker, R. (2012). Physicians' offices play key role in promoting vaccination to adult patients. Journal of the American Medical Association, 307(6), 552.

Williams, W. W., Lu, P., O’Halloran, A., Bridges, C. B., Pilishvili, T., Hales, C. M., \& Markowitz, L. E. (2014). Noninfluenza vaccination coverage among adults—United States, 2012. Morbidity and Mortality Weekly Report, 63(5), 95-102.

World Health Organization. (2011). Global routine vaccination coverage, 2010. Weekly Epidemiological Record, 86(46), 509-520.

World Health Organization. (2014). Global immunization data. Retrieved from http://www.who.int/immunization/monitoring_surveillance/Global_Immunization_Data.p df?ua $=1$ 
Table 1

Demographics

\begin{tabular}{llr}
\hline Demographic & Frequency & Percen \\
\hline Gender & & \\
Male & 127 & 15.5 \\
Female & 695 & 84.5
\end{tabular}

Age: Range 22 years -78 years

Mean (SD): 46 years $(11.324)$

Ethnicity

Caucasian

Hispanic

Non-Hispanic

96.2

$12 \quad 1.5$

Type of School

$19 \quad 2.3$

Elementary

Middle/Junior High $\quad 475$

84.5

High School

District Office

Multiple Schools

$15 \quad 1.8$

Current Occupation

Teacher

Administrator/Office Worker/Secretary/Counselor

66.4

Education Specialist/Computers/Librarian

Support Staff/Lunch Worker/Nurse/Custodian/Tracker

48

Other

25

44

19.4

5.8

3.0

5

Type of Employment

Full-time

Part-time

710

85.7

Other

114

13.8

4

0.5

Years Worked in School District: Range 1 year -55 years Mean (SD): 12.9 years (8.96) 
Table 2

\section{Current Vaccination Status}

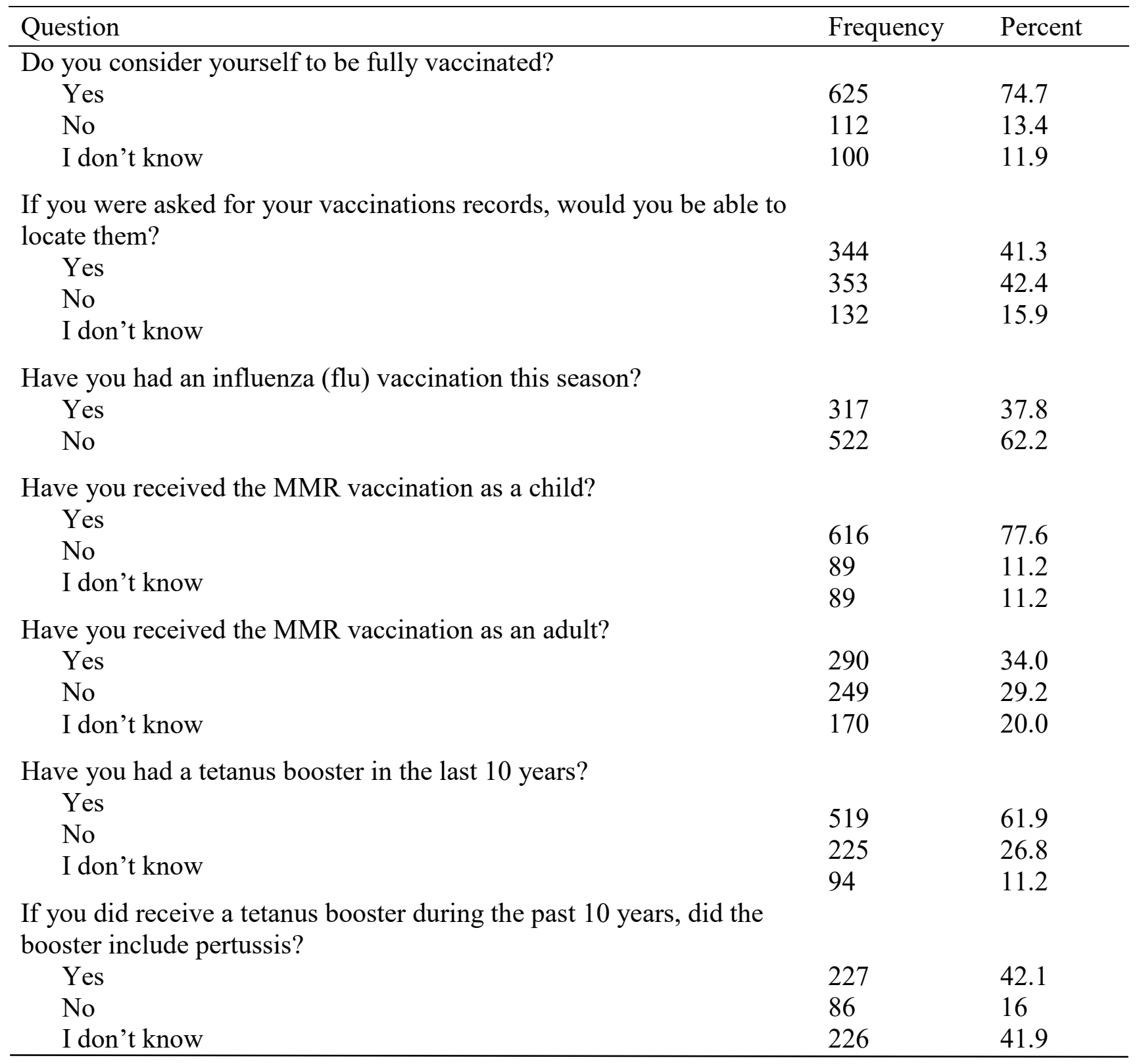


Table 3

Vaccination Perceptions

\begin{tabular}{|c|c|c|}
\hline Question & Frequency & Percent \\
\hline \multicolumn{3}{|l|}{ I believe vaccinations are safe. } \\
\hline Strongly Agree & 335 & 39.9 \\
\hline Agree & 445 & 53.0 \\
\hline No Opinion & 16 & 1.9 \\
\hline Disagree & 23 & 2.7 \\
\hline Strongly Disagree & 16 & 1.9 \\
\hline Other & 5 & 0.6 \\
\hline \multicolumn{3}{|c|}{ I believe vaccinations prevent disease. } \\
\hline Strongly Agree & 391 & 46.5 \\
\hline Agree & 403 & 48.0 \\
\hline No Opinion & 8 & 1.0 \\
\hline Disagree & 12 & 1.4 \\
\hline Strongly Disagree & 18 & 2.1 \\
\hline Other & 8 & 1.0 \\
\hline \multicolumn{3}{|c|}{ I believe it is important for adults to receive vaccinations. } \\
\hline Strongly Agree & 235 & 28.0 \\
\hline Agree & 435 & 51.8 \\
\hline No Opinion & 98 & 11.7 \\
\hline Disagree & 32 & 3.8 \\
\hline Strongly Disagree & 11 & 1.3 \\
\hline Other & 28 & 3.3 \\
\hline \multicolumn{3}{|c|}{$\begin{array}{l}\text { I believe it is important for school-aged children to receive } \\
\text { vaccinations. }\end{array}$} \\
\hline Strongly Agree & 555 & 66.1 \\
\hline Agree & 235 & 28.0 \\
\hline No Opinion & 7 & 0.8 \\
\hline Disagree & 7 & 0.8 \\
\hline Strongly Disagree & 24 & 2.9 \\
\hline Other & 12 & 1.4 \\
\hline \multicolumn{3}{|c|}{$\begin{array}{l}\text { I believe there are vaccination requirements for people employed by } \\
\text { the district. }\end{array}$} \\
\hline Yes & 46 & 5.5 \\
\hline No & 730 & 87.1 \\
\hline I don't know & 62 & 7.4 \\
\hline \multicolumn{3}{|c|}{$\begin{array}{l}\text { I believe school employees should have mandatory vaccination } \\
\text { requirements. }\end{array}$} \\
\hline Yes & 389 & 46.3 \\
\hline No & 227 & 27.0 \\
\hline Undecided & 224 & 26.7 \\
\hline
\end{tabular}


Table 4

Healthcare Provider Discussion

Question

Frequency

Percent

Has your healthcare provider discussed adult vaccinations with you?

Yes

352

42

No

465

55.5

I don't have a healthcare provider

21

2.5 
Table 5

Action Plan in the Event of a Measles Outbreak

Planned Action

Frequency

Percent

I have had an MMR booster so I'd stay at work.

I'm unsure of my MMR status but I'd stay at work.

161

19.5

I've already had the measles so I'd stay at work.

I have not had an MMR booster but I'd stay at work.

I have had an MMR booster but would stay at home.

I have not had an MMR booster so I'd stay at home.

I'm not sure of my MMR status so I'd stay home. 